\title{
Molecular characterisation of formalin-fixed paraffin-embedded (FFPE) breast tumour specimens using a custom 5 |2-gene breast cancer bead array-based platform
}

\author{
M Abramovitz',7, BG Barwick², S Willis ${ }^{3}$, B Young ${ }^{3}$, C Catzavelos ${ }^{4}$, Z Li', M Kodani $^{2,8}$, W Tang $^{2}$, M Bouzyk ${ }^{2}$, \\ CS Moreno ${ }^{2,5,6}$ and $B$ Leyland-Jones $*, 2,6$
}

'VM Institute of Research, 2020 University Street, Montreal, Quebec H3A 2A5, Canada; ${ }^{2}$ Emory Biomarker Service Centre, Emory University, $1365 C$ Clifton Road, N.E., Atlanta, GA 30322, USA; ${ }^{3}$ Scripps Research Institute Florida, 130 Scripps Way, Jupiter, FL 33458, USA; ${ }^{4}$ Department of Pathology, McGill University, Montreal, Quebec, Canada; ${ }^{5}$ Department of Pathology and Laboratory Medicine, Emory University School of Medicine, Atlanta, GA 30322, USA; 'Winship Cancer Institute, Robert W. Woodruff Health Sciences Centre, Emory University School of Medicine, I365C Clifton Road, N.E., Atlanta, GA 30322, USA

BACKGROUND: Formalin-fixed, paraffin-embedded (FFPE) tumour tissue represents an immense but mainly untapped resource with respect to molecular profiling. The DASL (cDNA-mediated Annealing, Selection, extension, and Ligation) assay is a recently described, RT-PCR-based, highly multiplexed high-throughput gene expression platform developed by Illumina specifically for fragmented RNA typically obtained from FFPE specimens, which enables expression profiling. In order to extend the utility of the DASL assay for breast cancer, we have custom designed and validated a 512-gene human breast cancer panel.

METHODS: The RNA from FFPE breast tumour specimens were analysed using the DASL assay. Breast cancer subtype was defined from pathology immunohistochemical $(\mathrm{IHC}$ ) staining. Differentially expressed genes between the $\mathrm{IHC}$-defined subtypes were assessed by prediction analysis of microarrays (PAM) and then used in the analysis of two published data sets with clinical outcome data.

RESULTS: Gene expression signatures on our custom breast cancer panel were very reproducible between replicates (average Pearson's $R^{2}=0.962$ ) and the 152 genes common to both the standard cancer DASL panel (Illumina) and our breast cancer DASL panel were similarly expressed for samples run on both panels (average $R^{2}=0.877$ ). Moreover, expression of ESRI, PGR and ERBB2 corresponded well with their respective pathology-defined $I \mathrm{HC}$ status. A 30-gene set indicative of $I \mathrm{HC}$-defined breast cancer subtypes was found to segregate samples based on their subtype in our data sets and published data sets. Furthermore, several of these genes were significantly associated with overall survival (OS) and relapse-free survival (RFS) in these previously published data sets, indicating that they are biomarkers of the different breast cancer subtypes and the prognostic outcomes associated with these subtypes.

CONCLUSION: We have demonstrated the ability to expression profile degraded RNA transcripts derived from FFPE tissues on the DASL platform. Importantly, we have identified a 30-biomarker gene set that can classify breast cancer into subtypes and have shown that a subset of these markers is prognostic of OS and RFS.

British Journal of Cancer (20II) I 05, I574- I58I. doi:I0.1038/bjc.201 I.355 www.bjcancer.com

(c) 20II Cancer Research UK

Keywords: breast cancer; DASL assay; bead array; formalin-fixed, paraffin-embedded (FFPE); relapse-free survival (RFS); overall survival (OS)

It is estimated that in the United States nearly 40000 women die from breast cancer every year, making breast cancer the second most frequent cause of cancer death (behind lung) among women (Jemal et al, 2008). Recent publications have methodically shown

\footnotetext{
* Correspondence: Professor B Leyland-Jones; E-mail: Leyland@emory.edu ${ }^{7}$ Current address: Departments of Pathology and Oncology, LDI and Segal Cancer Center, Jewish General Hospital, 3755 Cote Ste Catherine Road, Montreal, Quebec, Canada H3T IE2.

${ }^{8}$ Current address: Centres for Disease Control and Prevention, 1600 Clifton Road, N.E., Atlanta, GA 30333, USA.

Received I5 June 20 I I; revised I9 July 20 I I; accepted 7 August 20 I I
}

the heterogeneity of this disease (Wood et al, 2007) and a subsequent disparity in pathological course manifested between race/ethnicities (Carey et al, 2006; Stead et al, 2009).

Currently, breast cancer is divided into major subgroups based on the combined expression of the oestrogen receptor (ER), progesterone receptor (PR) and human epidermal growth factor receptor 2 (HER2). These subgroups have important implications in breast cancer aetiology, the systemic therapies prescribed and their expected effectiveness, and in the clinical outcome measured in both recurrence-free survival (RFS) and overall survival (OS) (Sørlie et al, 2001, 2006). The hormone receptor-positive (HR +) $(\mathrm{ER}+$ and/or PR + ), HER2-negative (HER2-) subtype appears to account for the majority of breast cancers $(>50 \%)$ and has the 
best prognosis because of effective targeted hormonal therapies and a more indolent disease phenotype. The two HER $2+$ subtypes $(\mathrm{HR}+/ \mathrm{HER} 2+$ and HR $-/$ HER $2+)$ account for $\sim 7 \%$ and $14 \%$, respectively. Before targeted therapy, HER $2+$ tumours portended some of the worst prognoses, but the development of targeted therapies, such as trastuzumab, has resulted in a marked improvement in outcome. The triple-negative (TN) subtype (defined as ER-, PR - and HER2-) comprises $10-30 \%$ of all invasive breast cancers. However, this estimation varies dramatically depending on race/ethnicity (Carey et al, 2006; Stead et al, 2009). In general, across all ethnic groups, TN breast cancer is considered a subtype that can often confer a poor clinical outcome. However, no effective targeted therapies have been devised to date for this subtype.

Gene expression profiling has become an important researchscreening tool in the identification and development of biomarkers that assess prognosis and prediction. Expression profiles have the potential to define cancer subtypes, prognosticate clinical outcome (i.e., recurrence of disease), predict response to specific therapies and identify critical oncogenic pathways (Huang et al, 2003). Investigations of signalling pathways and interactions indicated by gene signatures that are truly predictive of the clinical end points are necessary to understand the biology underlying this predictive value. When these gene signatures are combined with clinical and demographic factors, multiple forms of molecular (gene-based and protein) data can provide information that identifies unique tumour characteristics leading to individualised treatment strategies (van de Vijver et al, 2002; Nevins et al, 2003).

Although most array-based platforms utilise high-quality RNA prepared from frozen specimens, the newer DASL (cDNAmediated Annealing, Selection, extension and Ligation) assay (Illumina Inc., San Diego, CA, USA) was specifically designed to profile small fragmented transcripts typically extracted from formalin-fixed, paraffin-embedded (FFPE) tissues because of the formalin-fixation process (Bibikova et al, 2004; Fan et al, 2004; Li et al, 2006; Abramovitz et al, 2008). The DASL platform utilised in this study is based upon multiplexed RT - PCR applied in a bead array-based format that enables mRNA transcript quantification from up to 512 genes using three independent probe sets per gene and can be used to expression profile up to 96 samples in a highthroughput manner (Bibikova et al, 2004; Fan et al, 2004).

In an initial DASL assay study, a more limited 231-gene cancer panel was used in order to profile both breast and colon cancer FFPE tumour samples. Cluster analysis was able to separate breast from colon tissue types and subsequently divide each tissue sample set into cancer vs normal (Bibikova et al, 2004). In a subsequent study, Bibikova et al (2004) demonstrated the utility of Illumina's commercially available 502-gene human cancer panel to profile prostate, colon, breast and lung, and were able to identify differentially regulated genes between cancerous and healthy FFPE tissues. More recently, Ravo et al (2008) have shown, on a limited set of 13 breast carcinomas, that the DASL assay used in conjunction with the HCP is reliable and sensitive and compared favourably with results obtained by microarray analysis of RNA extracted from the same frozen tumour samples. The DASL assay has also been used, in conjunction with a panel of 512 prostaterelated genes, to identify RNA signatures in prostate cancer, including a 16-gene set that correlates with prostate cancer relapse (Bibikova et al, 2007).

In an effort to expand the utility of the DASL platform for breast cancer, we have designed a 512-gene custom human breast cancer panel (BCP) and used it to expression profile FFPE breast cancer tissue specimens currently not amenable for analysis on standard microarray platforms. Here we describe the validation of our 512-gene BCP and characterisation of breast cancer subtypes on the DASL bead array-based platform. We have identified a 30-gene set, which can be used to differentiate pathology-defined subtypes of breast cancer. Furthermore, several of these genes are prog- nostic of OS and RFS in publically available microarray data sets, indicating that they are valid biomarkers associated with the different outcomes related to the different breast cancer subtypes.

\section{MATERIALS AND METHODS}

\section{Tumour tissue samples}

Tumour samples from women with confirmed invasive carcinomas of the breast were obtained in the form of FFPE blocks. All archived FFPE tumour specimens were obtained from St Mary's Hospital (Montreal, Quebec, Canada) according to institutional guidelines. In total, we obtained 87 FFPE breast carcinomas that had previously been scored for the breast cancer markers, ER, PR and HER2 by immunohistochemistry (IHC) according to guidelines based on the ASCO/CAP recommendations for ER, PR and HER2 testing (ER/PR testing (http://www.cap.org/apps/docs/laboratory_ accreditation/summary_of_recommendations.pdf); HER2 testing (http://www.cap.org/apps/docs/committees/immunohistochemistry/ summary_of_recommendations.pdf)). In some IHC-equivocal cases of HER2 staining (IHC 2+), fluorescent in situ hybridisation (FISH) was used to confirm genomic amplification. The majority of the breast cancer tumour specimens used in this study were invasive ductal carcinomas (IDCs), including 2 tubular carcinomas and 1 invasive cribriform carcinoma; 2 of them had a sarcomatous component and 9 were mixed with invasive lobular carcinomas (ILCs). There were also 9 ILCs, the majority of which fell in the HR + subtype. The FFPE blocks were archived 2 to 3 years before analysis.

\section{RNA extraction, purification and quality assessment}

Three $5 \mu \mathrm{m}$ sections per FFPE block were used for RNA isolation. RNA deparaffinisation, extraction and purification were performed according to the High Pure FFPE RNA Micro Kit (Roche, Mannheim, Germany) protocol. RNA concentration and $\AA 260$ / $\AA 280$ ratio were determined using the NanoDrop ND-1000 spectrophotometer (NanoDrop Technologies Inc., Wilmington, DE, USA). In addition, TaqMan (Applied Biosystems, Foster City, CA, USA) assays were performed on the ribosomal protein RPL13a gene in triplicate using $200 \mathrm{ng}$ of RNA converted to cDNA to quantify usable copies of RNA molecules per sample. RNA quality was assessed by quantitative RT - PCR analysis of the housekeeping gene RPL13A (forward primer, 5'-GTACGCTGTGAAGGCAT CAA- $3^{\prime}$, and reverse primer, 5'-GTTGGTGTTCATCCGCTTG-3') and the reactions were run on a HT7900 real-time PCR instrument (Applied Biosystems).

\section{Custom breast cancer DASL assay pool (DAP)}

The custom breast cancer panel list of 512 candidate genes was submitted to Illumina for synthesis. The optimal oligonucleotide sequence for each of the 1536 gene probes was determined using an oligonucleotide-scoring algorithm. Illumina synthesised the oligonucleotide pool or DAP for the BCP for use with their 96-well Universal Array Matrix (UAM).

\section{DASL assay}

In the procedure, biotinylated random nonamers (biotin-d(N)9) and oligo $d(T) 18$ were used for cDNA synthesis and probes were designed such that they targeted unique regions of the gene without limiting the selection of the optimal probe to the $3^{\prime}$ ends of transcripts. Sequence-specific query oligonucleotides encompassing primer extension, ligation and universal PCR in highly multiplexed reactions (1536-plex), two-colour labelling and redundant $(\sim 30$-fold redundancy of each bead type) feature representation were used to probe up to three different exonic 
sites per gene. This protocol has been shown to increase assay sensitivity and reproducibility for quantitative detection of differential expression using RNA from FFPE tissues (Bibikova et al, 2004; Fan et al, 2004).

The DASL assay was performed on our 512-gene custom designed human BCP using $200 \mathrm{ng}$ of input RNA at the Emory Biomarker Service Centre (Emory University, Atlanta, GA, USA). The manufacturer's instructions were followed without modification. Samples, including technical replicates (singleton to quadruplicate), were run in the DASL assay on two UAMs. The hybridised UAMs were scanned using the BeadStation 500 Instrument (Illumina Inc.).

\section{Data and statistical analysis}

DASL transcript intensities were interpreted in GenomeStudio. Samples with insufficient signal-to-noise ratios $(<3)$ were removed from subsequent analysis and the remaining samples were quartile normalised with plate scaling. Technical replicates within samples were average combined to create one signature per tumour.

The 30-gene set used to differentiate subtypes was determined using prediction analysis of microarrays (PAM) (Tibshirani et al, 2002), which was optimised by minimising the cross-validation training error (see Supplementary Table 2). Hierarchical clustering was conducted in $\mathrm{R}$ using the heatmap. 2 package for each probe/ gene-level data (Free Software Foundation, Boston, MA, USA), which was $Z$-score normalised with a dissimilarity metric based on Euclidean distance and an average algorithm for clustering. Significance for ESR1, PGR and ERBB2 being differentially expressed between their respective IHC-positive and IHC-negative categories was assessed by Welch's $t$-test (Figure 1).

\section{Analysis of UNCCH-177 and NKI-295 cohorts}

Data for the 295 patients from the Netherlands Cancer Institute (NKI-295) (van de Vijver et al, 2002) study were downloaded from the NKI website (http://bioinformatics.nki.nl/data.php), and data for the 177 patients from the University of North Carolina Chapel Hill (UNCCH-177) (Parker et al, 2009) were downloaded from Gene Expression Omnibus (GSE10886). Outcome data for the two studies were obtained for the associated Supplementary Information for the two publications. When clustering the data using the 30 -gene set identified here, all probes for the given gene were used to cluster the data (Figure 3). Likewise, for the survival analysis of the 30 genes, all probes on the platforms for the NKI-295 and UNCCH-177 studies were analysed. One gene $(M L P H)$ was not found on the NKI-295 platform. The 30 genes identified by PAM (Supplementary Table 2) were analysed for association with RFS and overall survival OS in the UNCCH-177 and NKI-295 cohorts using the Cox proportional hazards method implemented in $\mathrm{R}$ by the function 'coxph' of the 'survival' package (Supplementary Tables 3 and 4). All results of the survival analyses used in this manuscript have been included in Supplementary Tables 3 and 4. The raw PAM analysis spreadsheet identifying the 30 subtype differentiating genes in our cohort has also been provided as Supplementary Table 5.

All files used in the data analysis of this manuscript have been included in the Supplementary materials.

\section{RESULTS}

\section{Design of the human custom BCP for use in the DASL assay}

In order to extend the utility of the DASL assay to the study of breast cancer utilising FFPE tumour specimens, we designed our own 512-gene BCP such that it incorporates previously identified signature genes from various breast cancer expression profiling studies that have been used in the intrinsic subclassification of breast tumours (Sørlie et al, 2001; Sotiriou et al, 2003), in prognosis (MammaPrint) (van't Veer et al, 2002) and as predictors of outcome to treatment (Ayers et al, 2004; Jansen et al, 2005; Pawitan et al, 2005), including OncotypeDX (Paik et al, 2004). We also selected genes taken from published data on breast cancer (McLean et al, 2005) as well as additional genes that have been implicated in a number of cancer-related processes including proliferation, angiogenesis (Zhong et al, 2000; Heuze-Vourc'h et al, 2005), metastasis (Kang et al, 2003; Minn et al, 2005), DNA repair, apoptosis (Miller et al, 2005) and thrombosis (Kwaan et al, 2003). Additional cancer-related genes included in the panel are oncogenes, tumour-suppressor genes, cell cycle genes, telomerase-related genes, amplified genes, breast cancer stem cell genes and senescence-related genes (Brabletz et al, 2005; Collado et al, 2005; Dikmen et al, 2005; see Supplementary Table 1 for the list of genes that make up the $\mathrm{BCP}$ ).

\section{Comparison to Illumina's human cancer panel}

In order to compare data generated with the $\mathrm{BCP}$ to data generated with the HCP, we evaluated 174 RNA samples that were composed of 6 singletons, 82 duplicates, 4 triplicates and 1 quadruplicate, making for 98 technical replicate correlations across 87 tumour specimens. Technical replicates run on the BCP and HCP had average correlations of 0.9612 and 0.9613 , respectively (Pearson's $r^{2}$ correlation, see Supplementary Figures $1 \mathrm{~A}$ and B). To further validate the $\mathrm{BCP}$, we compared data generated with the $\mathrm{BCP}$ against data previously generated with the HCP using a set of 152 genes present in both panels (see Supplementary Figure 1C).

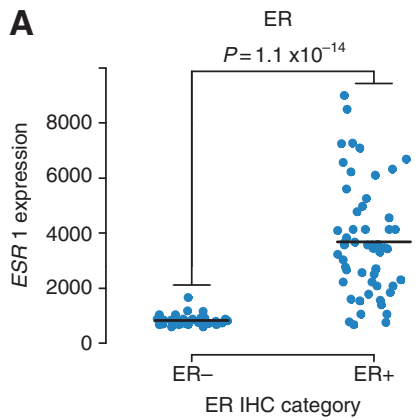

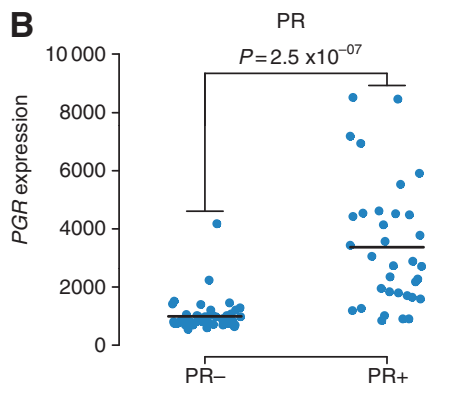

PR IHC category

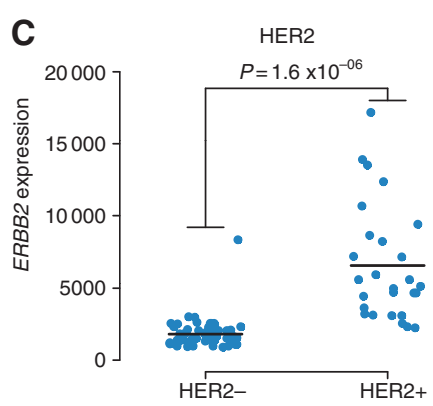

HER2 IHC category

Figure I Expression of ESRI, PGR and ERBB2 correspond to their respective pathology IHC staining status for ER, PR and HER2. Stripcharts showing the expression of $(\mathbf{A})$ ESRI, (B) PGR and (C) ERBB2 segregated by their respective negative and positive IHC categories. Gene-level data are displayed with the mean for each category denoted by the horizontal black bar and significance is assessed by a two-sided Welch's $t$-test. 

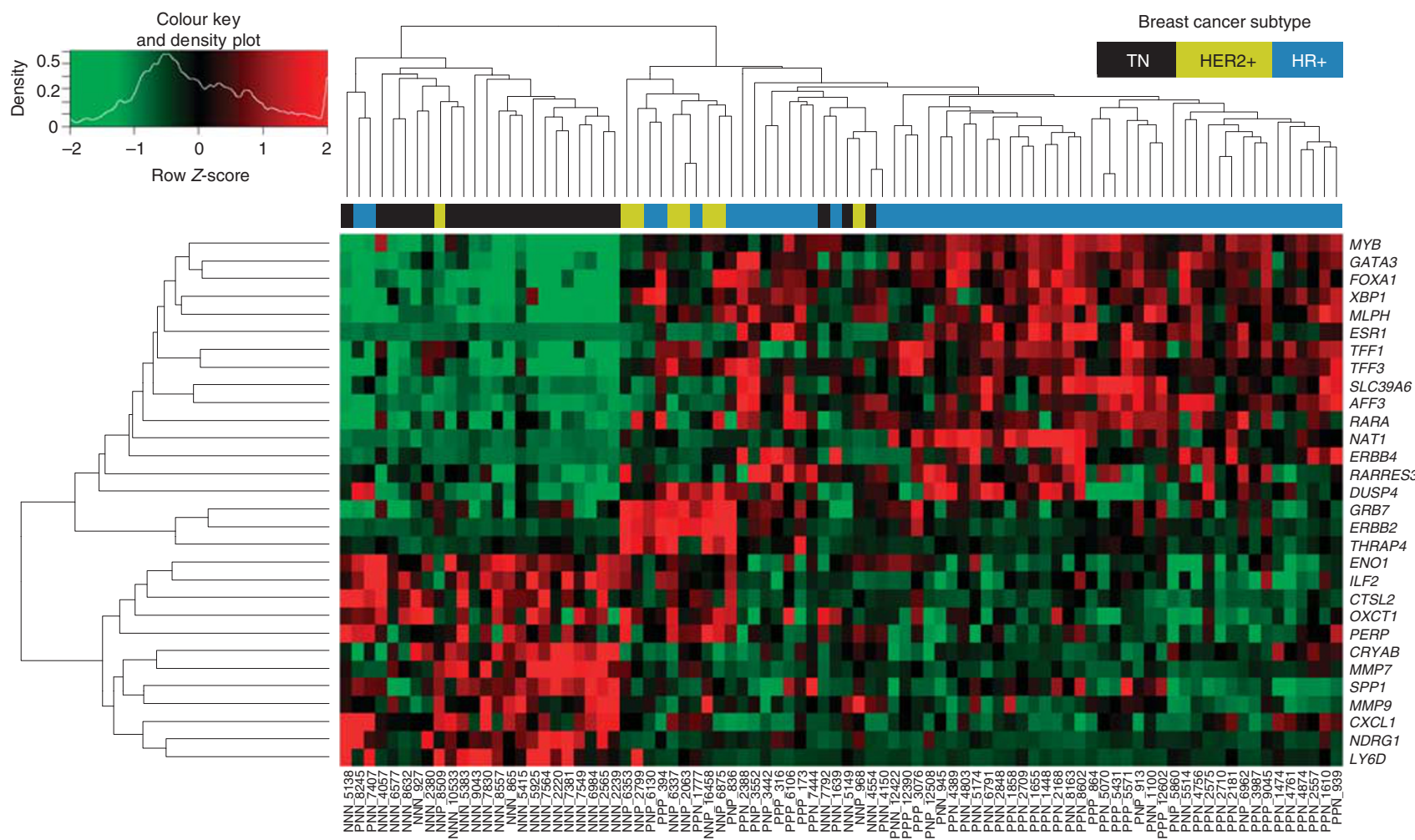

Figure 2 Montreal cohort of 87 patients hierarchically clustered across 30 genes predicative of immunohistochemical (IHC) breast cancer subtype. Prediction analysis of microarrays (PAM)-determined expression from 30 genes were indicative of IHC breast cancer subtype. Hierarchical clustering of patients (columns) and genes (rows) tends to segregate triple-negative (TN; indicated in black), HER2 + (indicated in yellow) and HR + (indicated in blue) tumours. Red indicates upregulation and green downregulation of transcripts for genes labelled on the right. Gene transcript expression levels are Z-score normalised with a colour key indicated in the top left corner

We compared 81 FFPE tumour samples analysed on both panels and observed an average $r^{2}$ correlation of 0.88 (see Supplementary Figure 1D). The lower correlation of technical replicates between panels, as compared with within panels, was most likely because of the intrinsic nature of competitive multiplexed PCR reactions using common primers with different sets of amplicons.

\section{Comparison of IHC data with DASL data for ER, PR and HER2}

A total of 87 FFPE tumour specimens came from three major IHC subclasses and were composed of 24 ER-/PR-/HER2- (designated TN); $8 \mathrm{ER}-/ \mathrm{PR}-/ \mathrm{HER} 2+($ designated HER $2+) ; 8 \mathrm{ER}+1$ PR-/HER2 + ; $11 \mathrm{ER}+/ \mathrm{PR}+/ \mathrm{HER} 2+$; $13 \mathrm{ER}+/ \mathrm{PR}-/ \mathrm{HER} 2-$; and $23 \mathrm{ER}+/ \mathrm{PR}+/$ HER - (designated $\mathrm{HR}+$ ).

To determine whether the DASL assay yields comparable data to IHC data, the DASL assay gene intensity (expression) data were compared with the available IHC protein expression data for ER, PR and HER2 on the set of 87 tumour samples. For purposes of comparison of IHC data with DASL data, the IHC data provided for ER and PR were scored as either negative for staining (IHC staining $<1 \%$; no expression detected) or as positive for staining (IHC staining $\geqslant 1 \%$; which included weak, moderate or strong expression). For HER2, a score of $3+$ was indicative of gene amplification (equivocal samples with a score of $2+$ were tested in the FISH assay in order to rule out gene amplification). The tumours positive and negative for ER, PR and HER2 showed a significantly different level of expression for their respective genes ESR1, PGR and ERBB2 $(P<0.01$, Welch's $t$-test; Figure 1). These data show that the concordance of DASL data with IHC data for all three receptors is very high, which is consistent with previous studies relating mRNA and IHC protein levels (Cronin et al, 2004; Gong et al, 2007).

Samples that stained positive for ER, PR and HER2 resulted in DASL mRNA average transcript fold changes in ESR1, PGR and ERBB2 $(95 \% \mathrm{CI})$ of $4.46(2.01-6.90), 3.41(1.24-5.58)$ and 3.59 (1.40-5.77) greater than their respective IHC-negative tumours. Taken together, these data indicate concordance of DASL assay intensity with IHC-determined protein expression. Of interest, among HER2 + tumour samples, expression levels were found to be highest in the HR- group compared with the HR + groups. This is consistent with previous work in which activated ER has been shown to downregulate expression of HER2 in human breast cancer cell lines (Russell and Hung, 1992).

\section{Analysis of the data by IHC subtype}

Unsupervised clustering of all samples was initially performed and clustering of the major subtypes, TN, HER $2+$ and HR +, is shown in Supplementary Figure 2. In order to define a set of genes that could be used to classify tumour samples, PAM (18) was used to identify 30 genes (Supplementary Table 2) that were indicative of the IHC breast cancer subtype in the Montreal cohort of 87 patients. Of these 30 genes, only 10 overlapped with Illumina's HCP. Additionally, 7 of the 30 genes overlapped with the PAM50 (FOXA1, MLPH, ESR1, SLC39A6, NAT1, GRB7 and ERBB2) (Parker et $a l, 2009)$ and 4 genes overlapped with OncotypeDX (ESR1, ERBB2, CTSL2 and GRB7), 3 of which (underlined) were common to all three gene sets (see Supplementary Figure 3). Unsupervised hierarchical clustering across the 30 genes, as shown in Figure 2, tended to segregate TN, HER2 + and HR + tumours. 

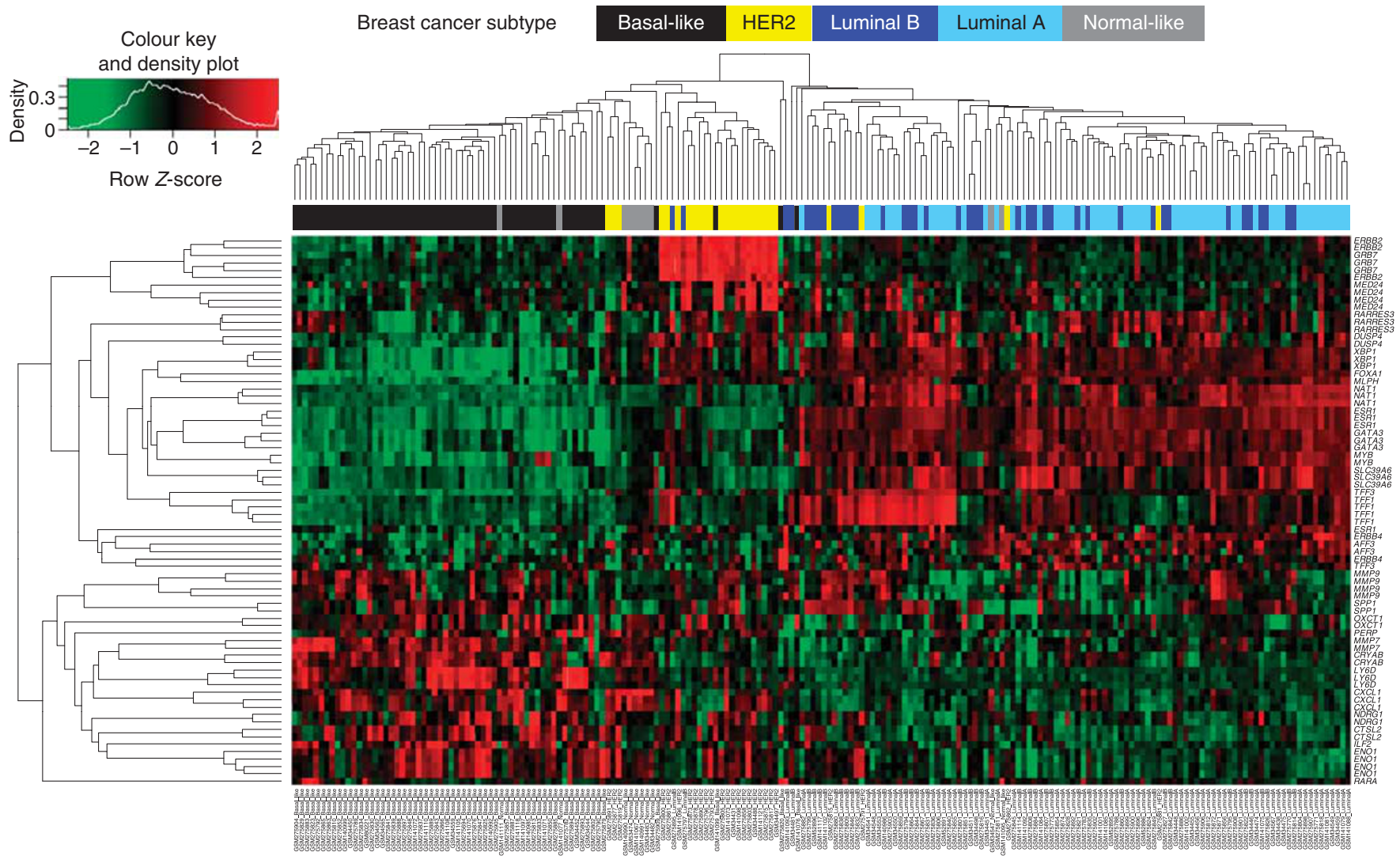

Figure 3 Hierarchical clustering of expression data from UNCCC cohort using probes from the 30 genes indicative of immunohistochemical (IHC) subtype in the Montreal cohort. Probes (rows) mapping to the 30 genes indicative of $\mathrm{HC}$ subtype were used to hierarchically cluster patients (columns) in the Parker et al (2009) published microarray data (GEO data set GSEI0886). These 30 genes segregate patients by 'intrinsic subtype'. Red indicates upregulation and green downregulation of transcripts for probes labelled on the right. Probe transcript expression levels are Z-score normalised with a colour key indicated in the top left corner. Hierarchical clustering was conducted in R using the heatmap.2 package, with a dissimilarity metric based on Euclidean distance and an average algorithm for clustering.

This 30-gene set was then applied to the University of North Carolina Chapel Hill Lineberger Comprehensive Cancer Centre (UNCCH) published microarray data set originally described by Parker et al (2009) in order to determine if it would reproduce the delineation of intrinsic subtypes defined independently. Using the UNCCH cohort data set $(n=177)$, unsupervised hierarchical clustering of the expression data using each probe for the 30 genes was performed and the heatmap is shown in Figure 3. The TN (basal-like), HER2 + and Normal-like clustered together whereas luminal B clusters were interspersed throughout the luminal A samples. Conversely, we also applied 33 genes of the PAM50 gene set, derived from fresh/frozen tissues and represented on the BCP, to our Montreal cohort with similar results (see Supplementary Figure 4). Thus, the 30-gene set applied to the UNCCH microarray data set was able to reproduce the delineation of intrinsic subtypes defined independently.

We then conducted an analysis of these 30 genes using the UNCCH data set as well as the NKI $(n=295)$ published breast cancer microarray data set (van de Vijver et al, 2002), with respect to OS and RFS (Supplementary Figure 5 and Supplementary Tables 3 and 4). Several of the genes were significant by univariate Cox regression analysis in both data sets. Although this analysis does not identify or recommend a prognostic based on these genes, it does suggest that the genes that differentiate subtype found on our custom breast DASL panel are of prognostic importance in other cohorts, further inferring our ability to identify relevant expression patterns from FFPE material.

\section{DISCUSSION}

In order to extend the utility of the DASL assay with respect to microarray analysis of FFPE breast cancer tumour specimens, which represent a vast archive of well-characterised clinically annotated samples (Lewis et al, 2001), we have designed a 512-gene custom BCP for use in the DASL assay to expression profile mRNA transcripts using RNA extracted from FFPE tissues. The RNA isolated from FFPE tissue sources is highly degraded (average size $\sim 175 \mathrm{nt}$ ) and chemically modified (Masuda et al, 1999), and hence not amenable for conventional microarray analysis. In the DASL assay, because of the small size of the targeted gene sequence $(\sim 50$ nucleotides), the use of random primers in the cDNA synthesis and three independent probe sets per gene are important factors that enable the expression profiling of degraded RNAs on this bead array-based platform using a minimal amount of total RNA (200 ng per assay).

Although FFPE samples used in this study were 2 to 3 years old, others have shown that older samples, despite increasing RNA degradation with age (Cronin et al, 2004), can also be used successfully in the DASL assay (Bibikova et al, 2004). It has also been recently shown that the DASL assay can generate comparable expression profiling data when directly comparing FFPE and fresh/ frozen tumour tissue pairs (Mittempergher et al, 2011). Taken together, there are many advantages to using the highly multiplexed DASL assay specifically for FFPE tumour samples that otherwise would not be easily amenable to other standard techniques such as RT-PCR, microarrays or RNA deep sequencing. 
Given that we were limited to expression profiling of 512 genes on the DASL platform, we designed our own BCP such that $70 \%$ (360 out of 512) of the genes differed from Illumina's commercial HCP resulting in a panel composed of genes specifically related to breast cancer pathology including those from the OncotypeDX (Paik et al, 2004) and MammaPrint (van de Vijver et al, 2002) as well as angiogenic, metastatic and other breast cancer prognostic and predictive markers. Our BCP also includes 33 of the 50 PAM50 genes from a recently published breast cancer biomarker study (Parker et al, 2009), indicative of selection of highly relevant genes.

We first validated our BCP for use in the DASL assay through concordance of DASL data with ER, PR and HER2 IHC data as well as by comparison of 152 genes in common with the HCP. The data clearly demonstrate that degraded RNA isolated from FFPE breast tumour specimens can be expression profiled using our BCP in a highly reproducible, accurate and high-throughput manner on the bead array-based DASL platform. Results from such analysis are consistent with clinical pathology IHC markers for ER, PR and HER2 and comparable to results from fresh/frozen specimens on traditional microarray platforms as demonstrated on independent published microarray-generated data sets (see below).

We used PAM analysis and identified 30 genes that were indicative of IHC breast cancer subtype that segregate the pathology-defined subtypes in an unsupervised hierarchical analysis. The majority of these genes (19 out of 30 ) have previously been associated with particular breast cancer subtypes (Rouzier et al, 2005; Hu et al, 2006; Parker et al, 2009) except 11 genes, including AFF3, DUSP4, ENO1, ERBB4, MMP7, MYB, PERP, RARA, SPP1, TFF1 and TFF3. This is not surprising as even biomarker signatures developed for women with similar breast tumour characteristics on similar microarray platforms and using only fresh/frozen extracted mRNA may not share many genes in common. For example, the Rotterdam 76-gene signature (Wang et al, 2005) and the 70-gene MammaPrint signature (van de Vijver et al, 2002) in fact share not a single gene in common.

There were two genes, in addition to HER2, clearly overexpressed in HER2 + tumours, GRB7 and MED24, which are both upstream of $E R B B 2$ on chromosome 17 and previously associated with the HER $2+$ subtype (Sørlie, 2004). Both GRB7 and MED24 have been found to be part of the smallest region of amplification (SRA), which extends from 34.73 to $35.48 \mathrm{Mb}$ in HER2-amplified tumours but does not include TOP2A (Arriola et al, 2008). Another gene further upstream on chromosome 17, the retinoic acid receptor (RARA), was only found to be overexpressed in only some of the HER 2 + tumour samples. The authors also found that in HER2/TOP2A co-amplified samples, the SRA that extended from 34.73 to $365.54 \mathrm{Mb}$ also encompassed four additional genes including RARA (Arriola et al, 2008). These genes that are co-amplified along with HER2 may also play a role in cancer progression. For example, evidence in breast cancer cell lines suggests that GRB7 may be involved in proliferation and that inhibiting both HER2 and GRB7 may enhance the inhibitory effect on cell growth (Pero et al, 2007).

When we applied our 30-gene set to published microarray data sets, we could reproduce the delineation of intrinsic subtypes defined independently. As it is well known that breast cancer subtypes have differing prognoses, we used these 30 genes to reanalyse two published breast cancer microarray studies, Parker et al (2009) and Van de Vijver et al (2002), with respect to OS and RFS. Seven genes were found prognostic of OS in both data sets and five of these seven were also prognostic of RFS. Several of these genes have previously been associated with the various subtypes. For example, ESR1, NAT1, SLC39A6 and XBP1 have been associated with the luminal A subtype (Sørlie, 2004), and CSTL2 and LYD6 are associated with the basal-like or TN subtype (Sørlie, 2004; Sørlie et al, 2006). In addition, we found that expression of NDRG1, which was prognostic of RFS but not OS, was mainly increased in TN tumours. This gene has been shown to be upregulated by hypoxic conditions and induced by the hypoxiainducible factor HIF1A, the key transcription factor involved in the response of tumours to hypoxic conditions. Genes involved in the cellular response to hypoxia, including NDRG1, are associated with a significantly poorer prognosis in breast and ovarian cancers (Chi et al, 2006).

In this study we have shown that it is feasible to use degraded RNA prepared from FFPE breast tumour specimens, which represent the largest collection of well-annotated, clinical tumour samples that are readily available for conducting large retrospective studies, for expression profiling on the DASL platform. We have demonstrated the utility of conducting expression profiling of breast tumour samples using a custom selected set of genes to investigate pathological processes related to subtype. To exemplify this, we have herein identified markers that can be used to classify breast cancer into subtypes consistent with independent means of classification and shown these markers to be prognostic of OS and RFS. Finally, this study is further evidence that expression profiling of FFPE tumour banks can be productive, something that has now been demonstrated many times, for example, in a series of published studies of the Oncotype DX tests (Paik et al, 2004; Tang et al, 2011) and that analysis of FFPE samples on the DASL assay could lead to the discovery of biomarker sets that will have relevance in the clinical setting.

\section{DATA DEPOSITION}

Gene Expression data are deposited in Gene Expression Omnibus (GEO) (http://www.ncbi.nlm.nih.gov/geo/) under series GSE17650.

\section{ACKNOWLEDGEMENTS}

We thank the Emory Biomarker Service Centre. This work was supported by funding from the Georgia Research Alliance and Winship Cancer Institute. CSM was supported by NIH R01 CA106826.

Supplementary Information accompanies the paper on British Journal of Cancer website (http://www.nature.com/bjc)

\section{REFERENCES}

Abramovitz M, Ordanic-Kodani M, Wang Y, Li Z, Catzavelos C, Bouzyk M, Sledge Jr GW, Moreno CS, Leyland-Jones B (2008) Optimization of RNA extraction from FFPE tissues for expression profiling in the DASL assay. Biotechniques 44: 417-423

Arriola E, Marchio C, Tan DS, Drury SC, Lambros MB, Natrajan R, Rodriguez-Pinilla SM, Mackay A, Tamber N, Fenwick K, Jones C, Dowsett M, Ashworth A, Reis-Filho JS (2008) Genomic analysis of the HER2/TOP2A amplicon in breast cancer and breast cancer cell lines. Lab Invest 88: $491-503$
Ayers M, Symmans WF, Stec J, Damokosh AI, Clark E, Hess K, Lecocke M, Metivier J, Booser D, Ibrahim N, Valero V, Royce M, Arun B, Whitman G, Ross J, Sneige N, Hortobagyi GN, Pusztai L (2004) Gene expression profiles predict complete pathologic response to neoadjuvant paclitaxel and fluorouracil, doxorubicin, and cyclophosphamide chemotherapy in breast cancer. J Clin Oncol 22: 2284-2293

Bibikova M, Chudin E, Arsanjani A, Zhou L, Garcia EW, Modder J, Kostelec M, Barker D, Downs T, Fan JB, Wang-Rodriguez J (2007) 
Expression signatures that correlated with Gleason score and relapse in prostate cancer. Genomics 89: 666-672

Bibikova M, Talantov D, Chudin E, Yeakley JM, Chen J, Doucet D, Wickham E, Atkins D, Barker D, Chee M, Wang Y, Fan JB (2004) Quantitative gene expression profiling in formalin-fixed, paraffin-embedded tissues using universal bead arrays. Am J Pathol 165: 1799-1807

Brabletz T, Jung A, Spaderna S, Hlubek F, Kirchner T (2005) Opinion: migrating cancer stem cells - an integrated concept of malignant tumour progression. Nat Rev Cancer 5: 744-749

Carey LA, Perou CM, Livasy CA, Dressler LG, Cowan D, Conway K, Karaca G, Troester MA, Tse CK, Edmiston S, Deming SL, Geradts J, Cheang MC, Nielsen TO, Moorman PG, Earp HS, Millikan RC (2006) Race, breast cancer subtypes, and survival in the Carolina Breast Cancer Study. JAMA 295: $2492-2502$

Chi JT, Wang Z, Nuyten DS, Rodriguez EH, Schaner ME, Salim A, Wang Y, Kristensen GB, Helland A, Børresen-Dale AL, Giaccia A, Longaker MT, Hastie T, Yang GP, van de Vijver MJ, Brown PO (2006) Gene expression programs in response to hypoxia: cell type specificity and prognostic significance in human cancers. PLoS Med 3: e47

Collado M, Gil J, Efeyan A, Guerra C, Schuhmacher AJ, Barradas M, Benguría A, Zaballos A, Flores JM, Barbacid M, Beach D, Serrano M (2005) Tumour biology: senescence in premalignant tumours. Nature 436: 642

Cronin M, Pho M, Dutta D, Stephans JC, Shak S, Kiefer MC, Esteban JM, Baker JB (2004) Measurement of gene expression in archival paraffinembedded tissues: development and performance of a 92-gene reverse transcriptase-polymerase chain reaction assay. Am J Pathol 164: $35-42$

Dikmen ZG, Gellert GC, Jackson S, Gryaznov S, Tressler R, Dogan P, Wright WE, Shay JW (2005) In vivo inhibition of lung cancer by GRN163L: novel human telomerase inhibitor. Cancer Res 65: 7866-7873

Fan JB, Yeakley JM, Bibikova M, Chudin E, Wickham E, Chen J, Doucet D, Rigault P, Zhang B, Shen R, McBride C, Li HR, Fu XD, Oliphant A, Barker DL, Chee MS (2004) A versatile assay for high-throughput gene expression profiling on universal array matrices. Genome Res 14: $878-885$

Gong Y, Yan K, Lin F, Anderson K, Sotiriou C, Andre F, Holmes FA, Valero V, Booser D, Pippen Jr JE, Vukelja S, Gomez H, Mejia J, Barajas LJ, Hess KR, Sneige N, Hortobagyi GN, Pusztai L, Symmans WF (2007) Determination of oestrogen-receptor status and ERBB2 status of breast carcinoma: a gene-expression profiling study. Lancet Oncol 8: $203-211$

Heuzé-Vourc'h N, Liu M, Dalwadi H, Baratelli FE, Zhu L, Goodglick L, Põld M, Sharma S, Ramirez RD, Shay JW, Minna JD, Strieter RM, Dubinett SM (2005) IL-20, an anti-angiogenic cytokine that inhibits COX-2 expression. Biochem Biophys Res Commun 333: 470-475

Hu Z, Fan C, Oh DS, Marron JS, He X, Qaqish BF, Livasy C, Carey LA, Reynolds E, Dressler L, Nobel A, Parker J, Ewend MG, Sawyer LR, Wu J, Liu Y, Nanda R, Tretiakova M, Ruiz Orrico A, Dreher D, Palazzo JP, Perreard L, Nelson E, Mone M, Hansen H, Mullins M, Quackenbush JF, Ellis MJ, Olopade OI, Bernard PS, Perou CM (2006) The molecular portraits of breast tumors are conserved across microarray platforms. BMC Genomics 7: 96

Huang E, Ishida S, Pittman J, Dressman H, Bild A, Kloos M, D'Amico M, Pestell RG, West M, Nevins JR (2003) Gene expression phenotypic models that predict the activity of oncogenic pathways. Nat Genet 34: $226-230$

Jansen MP, Foekens JA, van Staveren IL, Dirkzwager-Kiel MM, Ritstier K, Look MP, Meijer-van Gelder ME, Sieuwerts AM, Portengen H, Dorssers LC, Klijn JG, Berns EM (2005) Molecular classification of tamoxifenresistant breast carcinomas by gene expression profiling. J Clin Oncol 23: $732-740$

Jemal A, Siegel R, Ward E, Hao Y, Xu J, Murray T, Thun MJ (2008) Cancer statistics, 2008. CA Cancer J Clin 58: 71-96

Kang Y, Siegel PM, Shu W, Drobnjak M, Kakonen SM, Cordón-Cardo C, Guise TA, Massagué J (2003) A multigenic program mediating breast cancer metastasis to bone. Cancer Cell 3: 537-549

Kwaan HC, Parmar S, Wang J (2003) Pathogenesis of increased risk of thrombosis in cancer. Semin Thromb Hemost 29: 283-290

Lewis F, Maughan NJ, Smith V, Hillan K, Quirke P (2001) Unlocking the archive-gene expression in paraffin-embedded tissue. J Pathol 195: $66-71$

Li HR, Wang-Rodriguez J, Nair TM, Yeakley JM, Kwon YS, Bibikova M, Zheng C, Zhou L, Zhang K, Downs T, Fu XD, Fan JB (2006) Twodimensional transcriptome profiling: identification of messenger RNA isoform signatures in prostate cancer from archived paraffin-embedded cancer specimens. Cancer Res 66: 4079-4088

Masuda N, Ohnishi T, Kawamoto S, Monden M, Okubo K (1999) Analysis of chemical modification of RNA from formalin-fixed samples and optimization of molecular biology applications for such samples. Nucleic Acids Res 27: 4436-4443

McLean GW, Carragher NO, Avizienyte E, Evans J, Brunton VG, Frame MC (2005) The role of focal-adhesion kinase in cancer-a new therapeutic opportunity. Nat Rev Cancer 5: 505-515

Miller LD, Smeds J, George J, Vega VB, Vergara L, Ploner A, Pawitan Y, Hall P, Klaar S, Liu ET, Bergh J (2005) An expression signature for p53 status in human breast cancer predicts mutation status, transcriptional effects, and patient survival. Proc Natl Acad Sci USA 102: 13550-13555

Minn AJ, Gupta GP, Siegel PM, Bos PD, Shu W, Giri DD, Viale A, Olshen $\mathrm{AB}$, Gerald WL, Massagué J (2005) Genes that mediate breast cancer metastasis to lung. Nature 436: $518-524$

Mittempergher L, de Ronde JJ, Nieuwland M, Kerkhoven RM, Simon I, Rutgers EJ, Wessels LF, Van't Veer LJ (2011) Gene expression profiles from formalin fixed paraffin embedded breast cancer tissue are largely comparable to fresh frozen matched tissue. PLoS One 6: e17163

Nevins JR, Huang ES, Dressman H, Pittman J, Huang AT, West M (2003) Towards integrated clinico-genomic models for personalized medicine: combining gene expression signatures and clinical factors in breast cancer outcomes prediction. Hum Mol Genet 12 Spec No 2): R153 - R157

Paik S, Shak S, Tang G, Kim C, Baker J, Cronin M, Baehner FL, Walker MG Watson D, Park T, Hiller W, Fisher ER, Wickerham DL, Bryant J, Wolmark N (2004) A multigene assay to predict recurrence of tamoxifentreated, node-negative breast cancer. $N$ Engl J Med 351: 2817-2826

Parker JS, Mullins M, Cheang MC, Leung S, Voduc D, Vickery T, Davies S, Fauron C, He X, Hu Z, Quackenbush JF, Stijleman IJ, Palazzo J, Marron JS, Nobel AB, Mardis E, Nielsen TO, Ellis MJ, Perou CM, Bernard PS (2009) Supervised risk predictor of breast cancer based on intrinsic subtypes. J Clin Oncol 27: 1160-1167

Pawitan Y, Bjöhle J, Amler L, Borg AL, Egyhazi S, Hall P, Han X, Holmberg L, Huang F, Klaar S, Liu ET, Miller L, Nordgren H, Ploner A, Sandelin K, Shaw PM, Smeds J, Skoog L, Wedrén S, Bergh J (2005) Gene expression profiling spares early breast cancer patients from adjuvant therapy: derived and validated in two population-based cohorts. Breast Cancer Res 7: R953-R964

Pero SC, Shukla GS, Cookson MM, Flemer Jr S, Krag DN (2007) Combination treatment with Grb7 peptide and Doxorubicin or Trastuzumab (Herceptin) results in cooperative cell growth inhibition in breast cancer cells. Br J Cancer 96: $1520-1525$

Ravo M, Mutarelli M, Ferraro L, Grober OM, Paris O, Tarallo R, Vigilante A, Cimino D, De Bortoli M, Nola E, Cicatiello L, Weisz A (2008) Quantitative expression profiling of highly degraded RNA from formalin-fixed, paraffin-embedded breast tumor biopsies by oligonucleotide microarrays. Lab Invest 88: 430 - 440

Rouzier R, Perou CM, Symmans WF, Ibrahim N, Cristofanilli M, Anderson K, Hess KR, Stec J, Ayers M, Wagner P, Morandi P, Fan C, Rabiul I, Ross JS, Hortobagyi GN, Pusztai L (2005) Breast cancer molecular subtypes respond differently to preoperative chemotherapy. Clin Cancer Res 11: 5678-5685

Russell KS, Hung MC (1992) Transcriptional repression of the neu protooncogene by estrogen stimulated estrogen receptor. Cancer Res 52: $6624-6629$

Sørlie T (2004) Molecular portraits of breast cancer: tumour subtypes as distinct disease entities. Eur J Cancer 40: 2667-2675

Sørlie T, Perou CM, Tibshirani R, Aas T, Geisler S, Johnsen H, Hastie T, Eisen MB, van de Rijn M, Jeffrey SS, Thorsen T, Quist H, Matese JC, Brown PO, Botstein D, Eystein Lønning P, Børresen-Dale AL (2001) Gene expression patterns of breast carcinomas distinguish tumor subclasses with clinical implications. Proc Natl Acad Sci USA 98: 10869-10874

Sørlie T, Wang Y, Xiao C, Johnsen H, Naume B, Samaha RR, Børresen-Dale AL (2006) Distinct molecular mechanisms underlying clinically relevant subtypes of breast cancer: gene expression analyses across three different platforms. BMC Genomics 7: 127

Sotiriou C, Neo SY, McShane LM, Korn EL, Long PM, Jazaeri A, Martiat P, Fox SB, Harris AL, Liu ET (2003) Breast cancer classification and prognosis based on gene expression profiles from a population-based study. Proc Natl Acad Sci USA 100: 10393-10398

Stead LA, Lash TL, Sobieraj JE, Chi DD, Westrup JL, Charlot M, Blanchard RA, Lee JC, King TC, Rosenberg CL (2009) Triple negative breast cancers are increased in black women regardless of age or body mass index. Breast Cancer Res 11: R18 
Tang G, Shak S, Paik S, Anderson SJ, Costantino JP, Geyer Jr CE, Mamounas EP, Wickerham DL, Wolmark N (2011) Comparison of the prognostic and predictive utilities of the 21-gene Recurrence Score assay and Adjuvant! for women with node-negative, ER-positive breast cancer: results from NSABP B-14 and NSABP B-20. Breast Cancer Res Treat 127: $133-142$

Tibshirani R, Hastie T, Narasimhan B, Chu G (2002) Diagnosis of multiple cancer types by shrunken centroids of gene expression. Proc Natl Acad Sci USA 99: 6567-6572

Tusher VG, Tibshirani R, Chu G (2001) Significance analysis of microarrays applied to the ionizing radiation response. Proc Natl Acad Sci USA 98: $5116-5121$

van't Veer LJ, Dai H, van de Vijver MJ, He YD, Hart AAM, Mao M, Peterse HL, van der Kooy K, Marton MJ, Witteveen AT, Schreiber GJ, Kerkhoven RM, Roberts C, Linsley PS, Bernards R, Friend SH (2002) Gene expression profiling predicts clinical outcome of breast cancer. Nature 415: $530-536$

van de Vijver MJ, He YD, van't Veer LJ, Dai H, Hart AA, Voskuil DW, Schreiber GJ, Peterse JL, Roberts C, Marton MJ, Parrish M, Atsma D, Witteveen A, Glas A, Delahaye L, van der Velde T, Bartelink H, Rodenhuis
S, Rutgers ET, Friend SH, Bernards R (2002) A gene-expression signature as a predictor of survival in breast cancer. N Engl J Med 347: 1999-2009 Wang Y, Klijn JG, Zhang Y, Sieuwerts AM, Look MP, Yang F, Talantov D, Timmermans M, Meijer-van Gelder ME, Yu J, Jatkoe T, Berns EM, Atkins D, Foekens JA (2005) Gene-expression profiles to predict distant metastasis of lymph-node-negative primary breast cancer. Lancet 365: 671-679

Wood LD, Parsons DW, Jones S, Lin J, Sjöblom T, Leary RJ, Shen D, Boca SM, Barber T, Ptak J, Silliman N, Szabo S, Dezso Z, Ustyanksky V, Nikolskaya T, Nikolsky Y, Karchin R, Wilson PA, Kaminker JS, Zhang Z, Croshaw R, Willis J, Dawson D, Shipitsin M, Willson JK, Sukumar S, Polyak K, Park BH, Pethiyagoda CL, Pant PV, Ballinger DG, Sparks AB, Hartigan J, Smith DR, Suh E, Papadopoulos N, Buckhaults P, Markowitz SD, Parmigiani G, Kinzler KW, Velculescu VE, Vogelstein B (2007) The genomic landscapes of human breast and colorectal cancers. Science 318: $1108-1113$

Zhong H, Chiles K, Feldser D, Laughner E, Hanrahan C, Georgescu MM, Simons JW, Semenza GL (2000) Modulation of hypoxia-inducible factor lalpha expression by the epidermal growth factor/phosphatidylinositol 3-kinase/PTEN/AKT/FRAP pathway in human prostate cancer cells: implications for tumor angiogenesis and therapeutics. Cancer Res 60: $1541-1545$

This work is published under the standard license to publish agreement. After 12 months the work will become freely available and the license terms will switch to a Creative Commons Attribution-NonCommercial-Share Alike 3.0 Unported License. 